\title{
Efficient Light Harvesting and Energy Transfer in Organic-Inorganic Hybrid Multichromophoric Materials
}

\author{
Chih-Hsien Chen, ${ }^{\dagger, \downarrow}$ Ken-Yen Liu, ${ }^{\dagger}$ Sundarraj Sudhakar, ${ }^{\dagger}$ Tsong-Shin Lim,,${ }^{\S}$ Wunshain Fann,,$\$$ \\ Chao-Ping Hsu, ${ }^{\ddagger}$ and Tien-Yau Luh $*,+,, \| l$
}

Department of Chemistry and Institute of Polymer Science \& Engineering, National Taiwan University, Taipei, Taiwan 106, Institute of Chemistry, Academia Sinica, Taipei, Taiwan 115, and Institute of Atomic and Molecular Sciences, Academia Sinica, Taipei, Taiwan 106

Received: April 13, 2005; In Final Form: July 28, 2005

\begin{abstract}
Thin films of silica hybrid materials consisting of two to three covalently bound organic chromophores at different ratios were conveniently synthesized and fabricated. The photophysical properties of these materials have been studied. The fluorescence spectra reveal complete fluorescence resonance energy transfer (FRET) from donor to acceptor, and the light-harvesting ability of these hybrid materials increases with increasing the molar fraction of donor chromophore. In a three-chromophore system, the energy is transferred from 300 to $530 \mathrm{~nm}$ successfully. Time-resolved fluorescence experiments are employed to elucidate the average rates and efficiencies (84-97\%) of energy transfer in these organic/inorganic hybrid systems. The hybrid materials have been shown to provide antenna effect to facilitate energy transfer and light harvesting.
\end{abstract}

\section{Introduction}

There has been an ever-burgeoning interest in synthetic light harvesting systems to effectively mimic the natural process of energy transfer. Much attention has focused on organic or organometallic systems such as dendrimers, ${ }^{1}$ metalloporphyrin assemblies, ${ }^{2}$ or chromophore-functionalized polymers. ${ }^{3,4}$ Alternatively, Langmuir-Blodgett films, ${ }^{5}$ thin film, ${ }^{6}$ microspheres, ${ }^{7}$ monolayer, ${ }^{8}$ and self-assembled hydrogen-bound organic gel ${ }^{9}$ have also been used. Silica doped with organic dyes and transition-metal ions has been demonstrated to exhibit energytransfer properties. ${ }^{10}$ Hybrid organic-inorganic materials derived from sol-gel strategy offers great opportunities for the development of physics, chemistry, or biology in functional materials. ${ }^{11}$ In addition, the system provides a simple, fast, stable, and low cost process to fabricate the desired products. Indeed, chromophores covalently bound in sol-gel matrix are useful because leaching and phase separation of the dye molecule can be avoided, and the loading of chromophores can be tuned. ${ }^{11,12}$ It is envisaged that incorporation of more than two kinds of chromophores in such hybrid materials may provide an interesting model for studying the energy transfer between chromophores. Recently, a theoretical model has been developed on energy transfer in a multichromophoric system such as photosynthetic light-harvesting systems. ${ }^{13}$ The sol-gel method may offer a promising and convenient protocol to homogeneously disperse the chromophores in the hybrid systems in developing efficient artificial light-harvesting devices and in verifying for the multichromophoric photophysics anticipated. We now wish to report the synthesis, fabrication, and photophysical studies of a chromophore-containing organic-inorganic

\footnotetext{
* To whom correspondence should be addressed.

$\dagger$ Department of Chemistry, National Taiwan University.

$\doteqdot$ Institute of Chemistry, Academia Sinica.

$\S$ Institute of Atomic and Molecular Sciences, Academia Sinica.

"Institute of Polymer Science \& Engineering, National Taiwan University.
}

hybrid system where light harvesting and efficient energy transfer between donor and acceptor chromophores can readily occur.

\section{Results and Discussion}

Hybrid materials (A, containing chromophores stilbene (ST) and terphenylene-divinylene (TPDV); B, containing chromophores TPDV and hexathiophene (HT); C, containing chromophore ST and HT; D, containing chromophores ST, TPDV, and HT) were prepared by sol-gel techniques from a mixture of monomeric bis-ethoxysilanes $\mathbf{1 - 3}$ at different ratios. The precursors of these chromophores were synthesized in a manner similar to those described in the literature, and the details are described in the Supporting Information. ${ }^{14,15}$
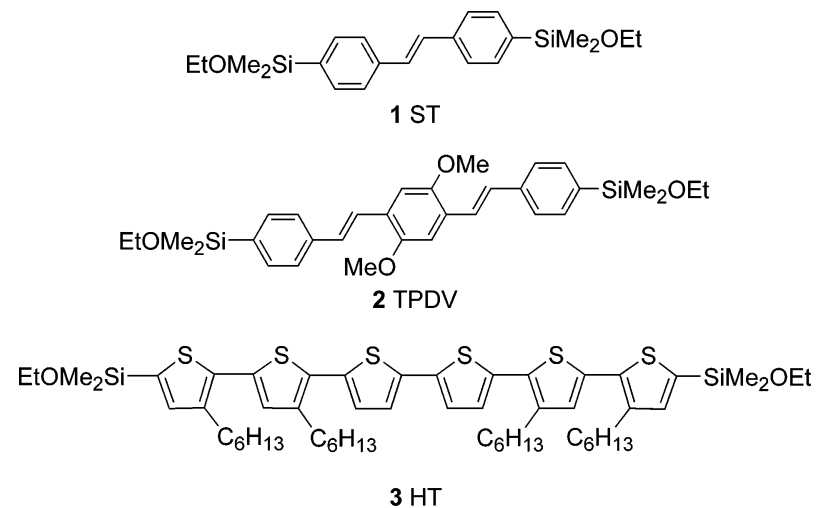

The photophysical properties and quantum yields of monomers $\mathbf{1 - 3}$ in ethyl acetate (EA) are summarized in Table 1.

Photophysical Behaviors between Two Chromophores. The absorption spectra of the hybrid materials A containing ST (donor chromophore) and TPDV (acceptor chromophore) at different ratios are shown in Figure 1a. The intensities of the absorption maxima due to ST and TPDV chromophores depended on the relative molar fractions of these two conjugated 
TABLE 1: Photophysical Properties of 1-3

\begin{tabular}{|c|c|c|c|c|c|c|}
\hline & $\begin{array}{c}\lambda_{\max },{ }^{a} \\
\mathrm{~nm}\end{array}$ & $\begin{array}{c}\lambda_{\max }{ }^{b} \\
\mathrm{~nm}\end{array}$ & $\begin{array}{c}\lambda_{\mathrm{em}}{ }^{a} \\
\mathrm{~nm}\end{array}$ & $\begin{array}{c}\lambda_{\mathrm{em}}{ }^{b} \\
\mathrm{~nm}\end{array}$ & $\begin{array}{l}\text { absorptivity, }{ }^{a}{ }^{\mathrm{L} \mathrm{mol}^{-1} \mathrm{~cm}^{-1}}\end{array}$ & $\begin{array}{l}\text { quantum } \\
\text { yield }^{c}\end{array}$ \\
\hline $1(\mathrm{ST})$ & 320 & 320 & 362 & 390 & $4.2 \times 10^{4}$ & 0.13 \\
\hline 2 (TPDV) & 395 & 400 & 445 & 480 & $5.2 \times 10^{4}$ & 0.54 \\
\hline 3 (HT) & 405 & 420 & 514 & 530 & $2.3 \times 10^{4}$ & 0.15 \\
\hline
\end{tabular}

${ }^{a}$ In ethyl acetate $(\mathrm{EA})$ solution (concentration: $5 \times 10^{-5} \mathrm{M}$ ). ${ }^{b}$ Hybrid thin film. ${ }^{c}$ Quantum yield relative to coumarin-1 $(\mathrm{QE}=0.99$ in EA).
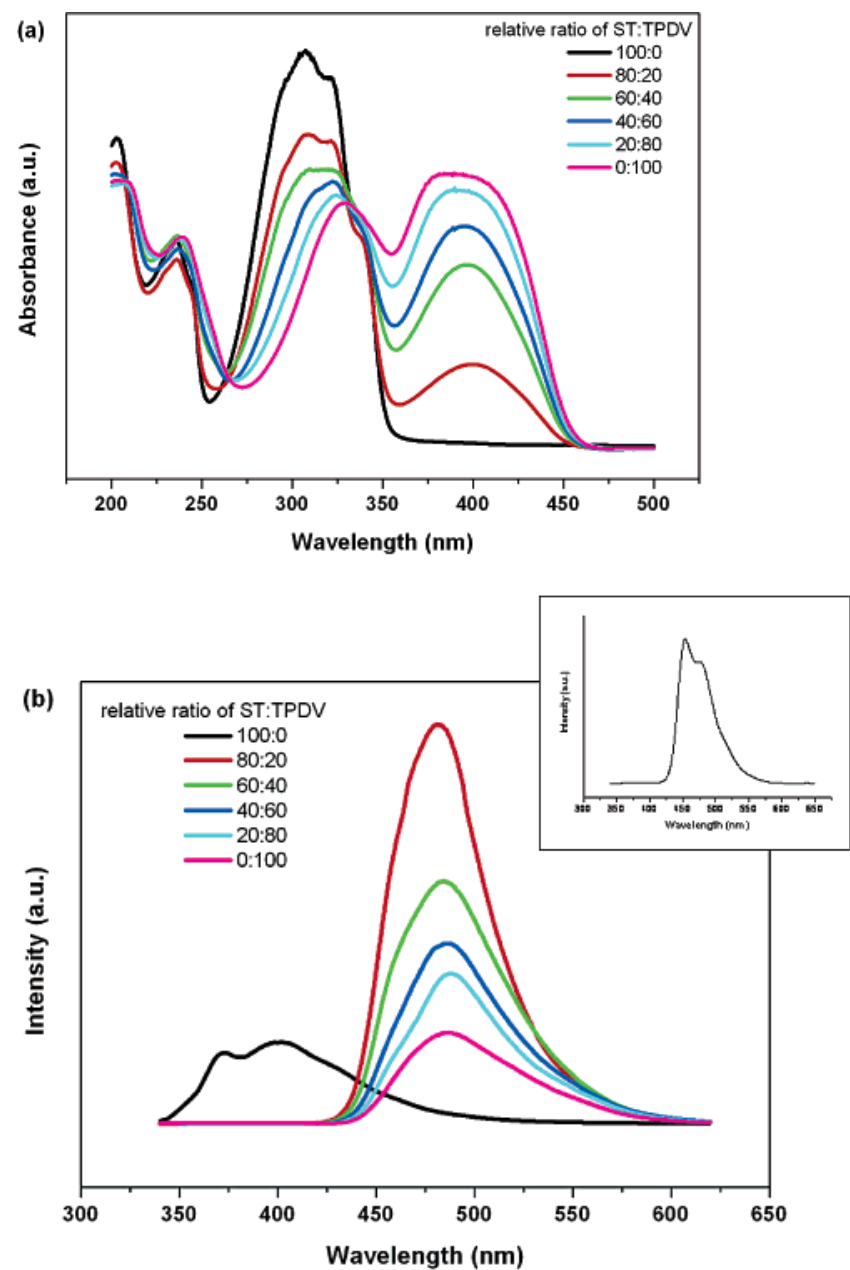

Figure 1. (a) Absorption and (b) emission spectra $\left(\lambda_{\mathrm{ex}}=300 \mathrm{~nm}\right)$ of hybrid materials $\mathbf{A}$ at different donor and acceptor ratios (TEOS to chromophore ratio 4:1). The inset shows emission spectra of donorto-acceptor ratio $45: 1$.

moieties. The emission profiles of $\mathbf{A}$ shown in Figure $1 \mathrm{~b}$ were obtained by excitation at $300 \mathrm{~nm}$. In the absence of TPDV, the emission of ST appeared at $390 \mathrm{~nm}$. When the ST to TPDV ratios were varied from 80:20 to 0:100, only characteristic emission due to TPDV with an emission maximum at $480 \mathrm{~nm}$ was observed. Even when the ratio of ST to TPDV was increased to 45:1, the emission from the ST chromophore was negligibly small. The intensity of TPDV emission became higher when the molar fraction of ST increased, indicating efficient energy transfer from ST donor to TPDV acceptor.

In a similar manner, hybrid materials $\mathbf{B}$ and $\mathbf{C}$ with different donor-to-acceptor ratios gave parallel results (Figures S5 and S6 in the Supporting Information). ${ }^{16 a}$ Excitation at 380 and $300 \mathrm{~nm}$ was chosen to furnish the corresponding emission spectra in $\mathbf{B}$ and $\mathbf{C}$, respectively. The characteristic emissions around $530 \mathrm{~nm}$ attributed to the HT acceptor in both hybrid materials $\mathbf{B}$ and $\mathbf{C}$ were observed when the donor-to-acceptor

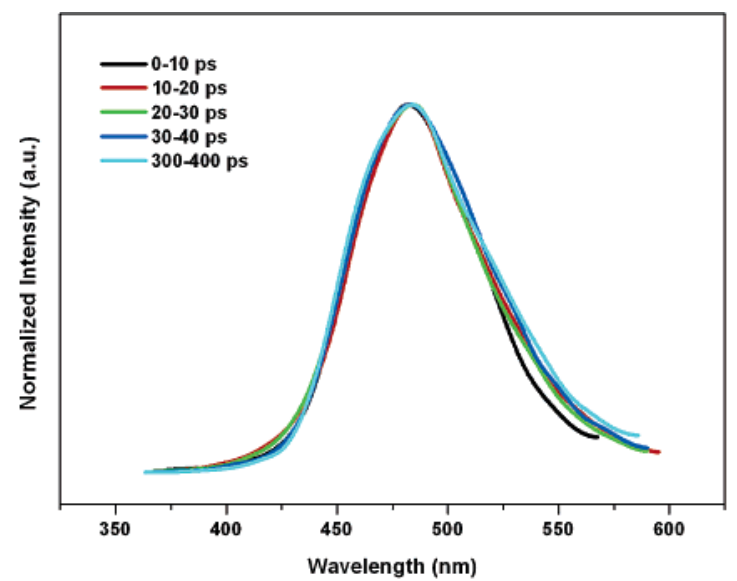

Figure 2. Normalized time-resolved fluorescence spectra $\left(\lambda_{\mathrm{ex}}=\right.$ $278 \mathrm{~nm})$ of $\mathbf{A}(\mathbf{1} / \mathbf{2}=4: 1)$.

ratios ranged from 80:20 to 0:100. Similarly, the intensity of emission was increased with increasing donor molar fraction, and emission due to donor chromophore was not observed. These results suggested that the donor and acceptor chromophores in $\mathbf{A}-\mathbf{C}$ appear to be homogeneously distributed in the hybrid silica matrixes.

Picosecond time-resolved fluorescence spectroscopy ${ }^{17}$ was employed to study the fluorescence lifetime and the rate of energy transfer from donor to acceptor in these hybrid materials. The fluorescence decay of hybrid films containing single chromophore ST exhibited the lifetime $30 \mathrm{ps,} \mathrm{whereas} \mathrm{the}$ lifetime for those hybrid materials constituting single chromophore TPDV or HT chromophores was 200 ps each.

Silica hybrid thin films $\mathbf{A}-\mathbf{C}$ with donor/acceptor $=80: 20$ were also subject to time-resolved fluorescence measurements. ${ }^{16 \mathrm{~b}}$ Figure 2 shows the typical time-resolved fluorescence spectra of hybrid film A. Similar spectra for $\mathbf{B}$ and $\mathbf{C}$ are shown in Figure S7 in the Supporting Information. Since the emission due to the donor in these systems was not observed, possibly due to the limitations of our instruments, the energy transfer rate was assumed to be faster than $1 \mathrm{ps}^{-1}$, which leads to an upper bound for energy transfer efficiency as $97 \%$. The high absorptivities of the chromophores (Table 1) and fast energy transfer rate indicate that the fluorescence resonance energy transfer (FRET) is responsible for the observed photophysics in these hybrid systems.

As shown in Figures 1, 2, and S7 (Supporting Information), efficient energy transfer was observed when the donor-toacceptor ratios ranged from 80:20 to 20:80. However, when the molar fraction of the donor was larger than 0.9 , the emission from the donor chromophore started to emerge. Such leak of donor emission may provide useful information on the efficiency of energy transfer in these hybrid systems. It is noteworthy that similar leak has been observed in dendrimeric systems of higher generation. ${ }^{1 \mathrm{~b}}$ Apparently, the distance between the donor chromophore and the acceptor chromophore may have played an important role here. ${ }^{1 b, g, 18,19} \mathrm{We}$ have therefore examined the detailed photophysical properties of these materials. The ratio of donor to acceptor was chosen to be $95: 5$ in all hybrid materials $\mathbf{A}-\mathbf{C}$. Time-resolved fluorescence spectra were measured (Figure 3), ${ }^{16 \mathrm{c}}$ and the efficiency of FRET in these systems could be represented by eq 1

$$
\eta=\sum_{i} D_{i} k_{\mathrm{ET} i} / \sum_{i} D_{i}\left(k_{\mathrm{EM}}+k_{\mathrm{ET} i}\right)
$$

where $k_{\mathrm{ET} i}$ is the rate of energy transfer between donor and 


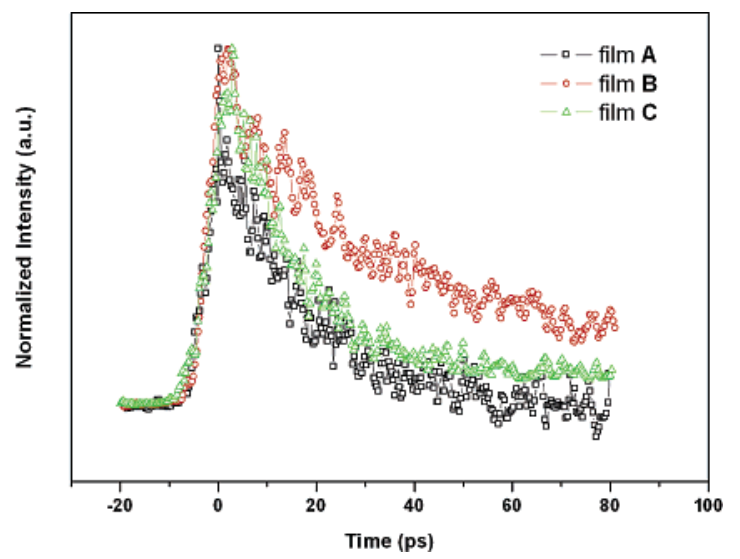

Figure 3. Time-resolved fluorescence decay of $\mathbf{A}$ (monitored at 380-390 nm), B (monitored at 470-480 nm), and $\mathbf{C}$ (monitored at 380-390 nm) with donor-to-acceptor ratio 95:5.

acceptor, which varies for different pairs. The rate constant $k_{\mathrm{EM}}$ is the intrinsic radiative and nonradiative decay of the donor chromophore at the excited state. $D_{i}$ is a constant for a given donor moiety in a hybrid film, and $\Sigma D_{i}$ is defined to be equal to 1 . In the hybrid systems, the distances between donor and acceptor chromophores would be different. Therefore, the rate of energy transfer should be a summation of each interaction between donor and acceptor chromophores. The time-resolved fluorescence decay profile $E(t)$ by experiments could be expressed as

$$
E(t)=\sum_{i} D_{i} \cdot e^{-\left(k_{\mathrm{EM}}+k_{\mathrm{ET} i}\right) t}
$$

At an early stage $(t \rightarrow 0), E(t)$ can be expanded by a Taylor series expansion:

$$
E(t)=\sum_{n=0}^{N} A_{n} t^{n}
$$

When $t \rightarrow 0$, eqs 2 and 3 can be expressed as eqs 4 and 5, respectively.

$$
\begin{gathered}
\lim _{\Delta t \rightarrow 0} \frac{E(t+\Delta t)-E(t)}{\Delta t}=\sum_{i}-\left(k_{\mathrm{EM}}+k_{\mathrm{ET} i}\right) D_{i} e^{-\left(k_{E M}+k_{E T i}\right) \cdot t} \\
\lim _{\Delta t \rightarrow 0} \frac{E(t+\Delta t)-E(t)}{\Delta t}=\sum_{n=1}^{N} n A_{n} t^{n-1}
\end{gathered}
$$

Since $\Sigma D_{i}=1$, eqs 4 and 5 can be combined:

$$
-A_{1}=\sum D_{i}\left(k_{\mathrm{E} M}+k_{\mathrm{ET} i}\right)=k_{\mathrm{EM}}+\sum_{i} D_{i} k_{\mathrm{ET} i}
$$

$A_{1}$ could be obtained by a polynomial fitting of the fluorescence decay curves. Accordingly, the denomenator in eq 1 can be obtained and the term $k_{\mathrm{EM}}$ could be estimated by the fluorescence lifetime described above. The efficiency shown in eq 1 can thus be calculated, and the detailed calculations are described in the Supporting Information.

Based on eq 1, the efficiencies of energy transfer in these hybrid materials $\mathbf{A}-\mathbf{C}$ (donor/acceptor $=95: 5$ ) were calculated to be $91 \%, 94 \%$, and $84 \%$, respectively. The FRET between ST and TPDV and between TPDV and HT were more efficient than that between ST and HT. Factors such as the overlap of the donor emission spectrum and the acceptor absorption
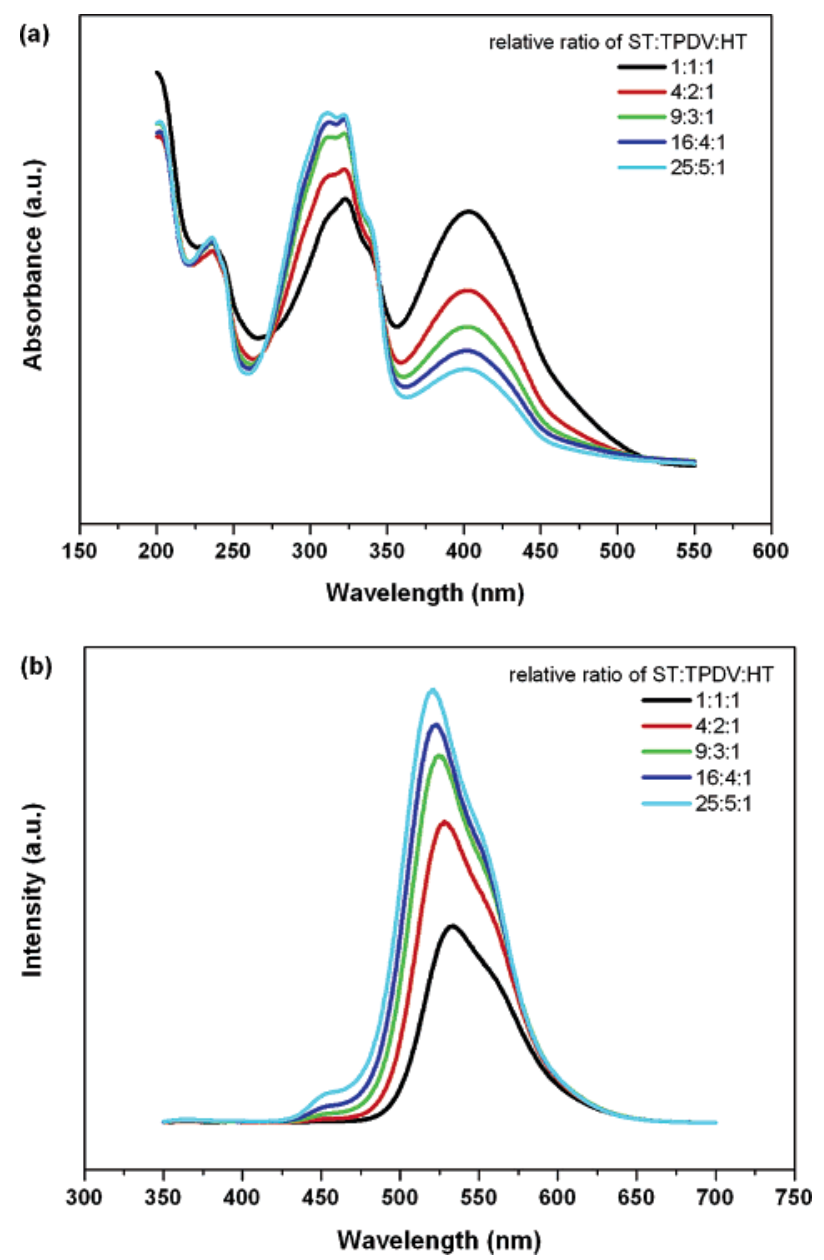

Figure 4. (a) Absorption and (b) emission spectra $\left(\lambda_{\mathrm{ex}}=300 \mathrm{~nm}\right)$ of D with different donor-to-acceptor ratios (TEOS to chromophores ratio $4: 1)$.

spectrum, quantum yield of donor, and lifetime of emission derived from donor may contribute the energy transfer efficiency. ${ }^{19}$ The small efficiency of $\mathbf{C}$ is in agreement with the largest separation of donor emission and acceptor absorption frequencies (Table 1), leading to the smallest spectral overlap among the three hybrid materials $\mathbf{A}-\mathbf{C}$ and thus a decreased FRET rate.

Light Harvesting and Energy Transfer in Three-Chromophore System. Hybrid materials D consisting of chromophores ST, TPDV, and HT at different ratios were also subject to photophysical measurements (Figure 4). When the system was excited at $300 \mathrm{~nm}$, the fluorescence maximum at $530 \mathrm{~nm}$ due to the emission of HT was observed in all these cases.

The energy transfer was quite efficient in film $\mathbf{D}$, when the chromophore ratio (ST/TPDV/HT) was 1:1:1, only emission of the acceptor chromophore derived from HT being observed at different delayed times (Figure 5a). As described previously, the energy transfer was too fast to be monitored by means of picosecond time-resolved fluorescence measurements and, therefore, the efficiency was estimated to be at least $97 \%$.

As shown in Figure 4b, a small emission peak around $470 \mathrm{~nm}$ was observed in D when the ratios of the starting chromophores (ST/TPDV/HT) were 16:4:1 and 25:5:1. Presumably, this additional emission may be due to the leak from intermediate chromophore TPDV. It is interesting to note that the molar fraction of the final acceptor chromophore HT in these materials is less than 0.05 , and the energy transfer may become 

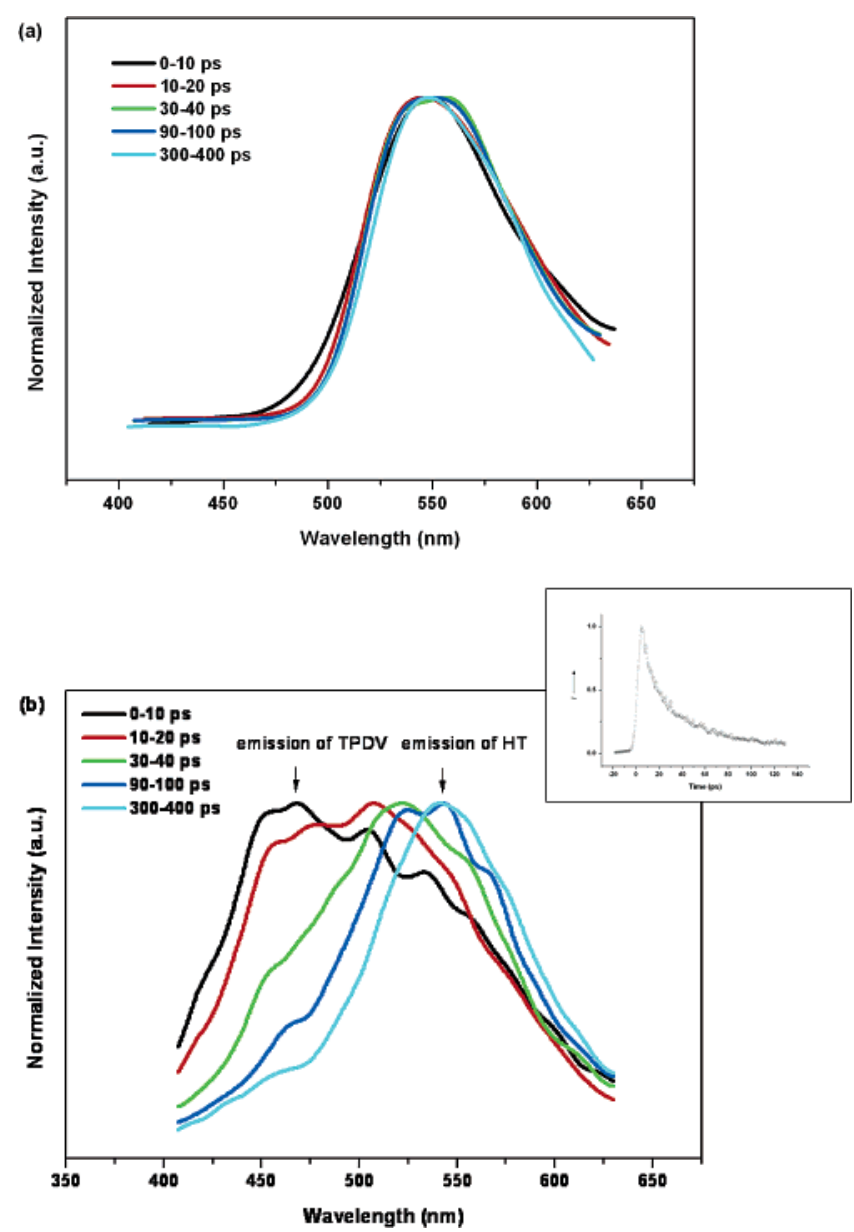

Figure 5. Normalized time-resolved fluorescence spectra $\left(\lambda_{\mathrm{ex}}=\right.$ $278 \mathrm{~nm}$ ) of $\mathbf{D}$ with (a) $\mathbf{1 / 2} / \mathbf{3}=1: 1: 1$ and (b) $\mathbf{1 / 2} / \mathbf{3}=16: 4: 1$. The inset shows fluorescence decay profile monitored at $460-470 \mathrm{~nm}$.

less efficient because the distance between certain donor and acceptor moieties might be far apart.

Time-resolved fluorescence studies revealed that the intensity at $470 \mathrm{~nm}$ gradually decreased with increasing delay time and diminished around 300-400 ps (Figure 5b), and the efficiency of energy transfer was estimated to be $88 \%$ (from ST to HT) in this system $(\mathrm{ST} / \mathrm{TPDV} / \mathrm{HT}=16: 4: 1)$.

\section{Conclusions}

In summary, we have demonstrated a convenient sol-gel protocol to fabricate organic-inorganic hybrid materials $\mathbf{A}-\mathbf{D}$. The starting precursors are readily accessible and the chromophores with different ratios were assembled homogeneously. We have clearly observed efficient light-harvesting in all of these hybrid systems. The fluorescence spectra revealed complete energy transfer from donor to acceptor, and the light-harvesting ability of these hybrid materials was enhanced as the molar fraction of donor was increased. In three-chromophore system D, the energy could be efficiently transferred from 300 to $530 \mathrm{~nm}$ successfully. It seems likely that the FRET may play a significant role in the overall excited-state energy transfer. These systems have provided comparable antenna effect and efficiency of energy transfer to those of dendrimers ${ }^{1}$ and related systems.

\section{Experimental Section}

Preparation of Organic-Inorganic Hybrid Sol-Gel Thin Film. Hybrid silica materials containing a combination of two or three kinds of chromophores were prepared by the sol-gel technique. In a typical procedure, treatment of a mixture of $\mathbf{1}$ and 2 in different ratios (total amount $=0.03 \mathrm{mmol}$ ) with 4 equiv of TEOS $(27 \mu \mathrm{L}, 0.12 \mathrm{mmol})$ and 9 equiv of water $(5 \mu \mathrm{L}, 0.27 \mathrm{mmol})$ in the presence of a catalytic amount $(0.6 \mathrm{mg}, 0.0024 \mathrm{mmol})$ of TBAF in THF $(0.45 \mathrm{~mL})$ afforded the corresponding sol solution which was spin-coated on a quartz plate. The film was allowed to stand at room temperature for $1 \mathrm{~h}$ in the dark and was used for spectroscopic measurements. The thickness of sol-gel thin films was measured by scanning electron microscope (SEM), and the average thickness was about $300 \mathrm{~nm}$ (Figure S1, Supporting Information).

Instrumentation. Absorption spectra were measured with a Hitachi U-3310 spectrophotometer and emission spectra with a Hitachi F-4500 fluorescence spectrophotometer. The micrographs were obtained with a LEO 1530 field emission scanning electron microscope. In time-resolved fluorescence experiments, a mode-locked Ti:sapphire laser (wavelength, $820 \mathrm{~nm}$; repetition rate, $76 \mathrm{MHz}$; pulse width, $<200 \mathrm{fs}$ ) passed through an optical parametric amplifier. The fluorescence of sample was reflected by a grating $(150 \mathrm{~g} / \mathrm{mm}$; BLZ: $300 \mathrm{~nm})$ and detected by an optically triggered streak camera (Hamamatsu C5680) with a time resolution of about $0.3 \mathrm{ps}$.

Acknowledgment. We thank the National Science Council, the Ministry of Education, and Academia Sinica of the Republic of China for support.

Supporting Information Available: Experimental procedures, Figures $\mathrm{S} 1-\mathrm{S} 8$, and data treatment from time-resolved fluorescence studies.

\section{References and Notes}

(1) (a) Stewart, G. M.; Fox, M. A. J. Am. Chem. Soc. 1996, 118, 4354 (b) Devadoss, P.; Moore, J. S. J. Am. Chem. Soc. 1996, 118, 9635. (c) Jiang, D.-L.; Aida, T. Nature 1997, 388, 454. (d) Gilat, S. L.; Adronov, A.; Fréchet, J. M. J. Angew. Chem., Int. Ed. 1999, 38, 1422. (e) Plevoets, M.; Vögtle F.; Cola, L. D.; Balzani, V. New J. Chem. 1999, 23, 63 (f) Adronov, A.; Fréchet, J. M. J. Chem. Commun. 2000, 1701. (g) Adronov, A.; Gilat, S. L.; Fréchet, J. M. J.; Ohta, K.; Neuwahl, F. V. R.; Fleming, G. R. J. Am. Chem. Soc. 2000, 122, 1175. (h) Serin, J. M.; Brousmiche, D. W.; Fréchet, J. M. J. Chem. Commun. 2002, 2605. (i) Melinger, J. S.; Pan, Y.; Kleiman, V. D.; Peng, Z.; Davis, B. L.; McMorrow, D.; Lu, M. J. Am. Chem. Soc. 2002, 124, 12002.

(2) (a) Haycock, R. A.; Yartsev, A.; Michelsen, U.; Sundström, V.; Hunter, C. A. Angew. Chem., Int. Ed. 2000, 39, 3616. (b) Nakano, A.; Osuka, A.; Yamazaki, T.; Nishimura, Y.; Akimoto, S.; Yamazaki, I.; Itaya, A.; Murakami, M.; Miyasaka, H. Chem. Eur. J. 2001, 7, 3134. (c) Gust, D.; Moore, T. A.; Moore, A. L. Acc. Chem. Res. 2001, 34, 40. (d) Choi, M.-S.; Aida, T.; Yamazaki, T.; Yamazaki, I. Chem. Eur. J. 2002, 8, 2667. (e) Tomizaki, K.; Loewe, R. S.; Kirmaier, C.; Schwartz, J. K.; Retsek, J. L.; Bocian, D. F.; Holten, D.; Lindsey, J. S. J. Org. Chem. 2002, 67, 6519.

(3) (a) Nowakowska, M.; Foyle, P. V.; Guillet, J. E. J. Am. Chem. Soc. 1993, 115, 5975. (b) Hisada, K.; Ito, S.; Yamamoto, M. Langmuir 1995, 11, 996. (c) Schultze, X.; Serin, J.; Adronov, A.; Fréchet, J. M. J. Chem. Commun. 2001, 1160. (d) Russel, D. M.; Arias, C. A.; Friend, R. H.; Silvia, C.; Ego, C.; Grimsdale, A. C.; Müllen, K. Appl. Phys. Lett. 2002, $80,2204$.

(4) (a) Cheng, Y.-J.; Hwu, T.-Y.; Hsu, J.-H.; Luh, T.-Y. Chem. Commun. 2002, 1978. (b) Cheng, Y.-J.; Liang, H.; Luh, T.-Y. Macromolecules 2003, 36, 5912. (c) Cheng, Y.-J.; Luh, T.-Y. Chem. Eur. J. 2004, 10,5361 .

(5) (a) Morita, T.; Kimura, S.; Imanasi, Y. Langmuir 1998, 14, 171. (b) Matsui, J.; Mitsuishi, M.; Miyashita, T. Macromolecules 1999, 32, 381 (c) Dutton, P. J.; Conte, L. Langmuir 1999, 15, 613.

(6) (a) Kaschak, D. M.; Mallouk, T. E. J. Am. Chem. Soc. 1996, 118 4222. (b) Kaschak, D. M.; Lean, J. T.; Warakska, C. C.; Saupe, G. B. Usami, H.; Mallouk, T. E. J. Am. Chem. Soc. 1999, 121, 3435.

(7) (a) Charreyre, M.-T.; Yekta, A.; Winnik, M. A.; Delai, T.; Pichot, C. Langmuir 1995, 11, 2423. (b) Caruso, F.; Donath, E.; Mowhald, H. J. Phys. Chem. B 1998, 102, 2011.

(8) Chrisstoffels, L. A. J.; Adronov, A.; Fréchet, J. M. J. Angew. Chem., Int. Ed. 2000, 39, 2163.

(9) Ajayaghosh, A.; George. S. J.; Praveen, V. K. Angew. Chem., Int. Ed. 2003, 42, 332 . 
(10) (a) Judeinstein, P.; Sanchez, C. J. Mater. Chem. 1996, 6, 511. (b) Chujo, Y. Curr. Opin. Solid State Mater. Sci. 1996, 1, 806. (c) Wen, J. Wilkes, G. L. Chem. Mater. 1996, 8, 1667. (d) Barton, T. J.; Bull, L. M.; Klemperer, W. G.; Loy, D. A.; McEnaney, B.; Misono, M.; Monson, P. A.; Pez, G.; Scherer, G. W.; Vartuli, J. C.; Yaghi, O. M. Chem. Mater. 1999, 11, 2633. (e) Corriu, R. Eur. J. Inorg. Chem. 2001, 1109. (f) Corriu, R. J. P. J. Organomet. Chem. 2003, 686, 32. (g) Boury, B.; Corriu, R. J. P. Chem. Rec. 2003, 3, 120.

(11) Gomez-Romero, P.; Sanchez, C. Functional Hybrid Materials; Wiley-VCH: Weinheim, 2004.

(12) (a) L'Espérance, D.; Chronister, E. L. Chem. Phys. 1995, 195, 387. (b) Buddhudu, S.; Morita, M.; Murakami, S.; Rau, D. J. Lumin. 1999, 83, 199. (c) Embert, F.; Mehdi, A.; Reye, C.; Corriu, R. J. P. Chem. Mater. 2001, 13, 4542. (d) Tamilselvan, S.; Bullen, C.; Ashokkumar, M.; Mulvaney, P. Adv. Mater. 2001, 13, 985. (e) Deshpande, A. V.; Panhalkar, R. R. J. Lumin. 2002, 96, 185.

(13) (a) Fleming, G. R.; Scholes, G. D. Nature 2004, 431, 256. (b) Jang, S. J.; Newton, M. D., Silbey, R. J. Phys. Rev. Lett. 2004, 92, 218301
(14) (a) Chen, R.-M.; Chien, K.-M.; Wong, K.-T.; Jin, B.-Y.; Luh, T.Y: Hsu, J.-H.; Fann, W.-S. J. Am. Chem. Soc. 1997, 119, 11321. (b) Sudhakar, S.; Luh, T.-Y. J. Org. Chem. 2002, 67, 6860.

(15) Azumi, R.; Götz, G.; Debaerdemaeker, T.; Bäuerle, P. Chem. Eur J. 2000, 6, 735 .

(16) (a) The fluorescence spectra are shown in the Supporting Information (Figures S5 and S6). (b) Time-resolved fluorescence spectra of $\mathbf{B}$ and C with donor-to-acceptor ratio 80:20 are shown in the Supporting Information (Figure S7). (c) Time-resolved fluorescence spectra of $\mathbf{A}-\mathbf{C}$ with donor-to-acceptor ratio 95:5 are shown in the Supporting Information (Figure S8).

(17) The detailed calculations of time-resolved data are described in the Supporting Information.

(18) (a) Krueger, B. P.; Scholes, G. D.; Fleming, G. R. J. Phys. Chem. B 1998, 102, 5378. (b) Blumen, A.; Manz, J. J. Chem. Phys. 1979, 71 4694.

(19) (a) Förster, T. Ann. Phys. 1948, 2, 55. (b) Förster, T. Z. Naturforsch., A 1949, 4, 321 . 